\title{
The Client Attachment to Therapist Scale (CATS) in a Greek Clinical Population: A Validation Study
}

\author{
Vasiliki Yotsidi, Christos Pezirkianidis, Eirini Karakasidou, Anastassios Stalikas \\ Panteion University of Social and Political Sciences, Athens, Greece \\ Email: irenekarakasidou@yahoo.com
}

How to cite this paper: Yotsidi, V., Pezirkianidis, C., Karakasidou, E. and Stalikas, A. (2018) The Client Attachment to Therapist Scale (CATS) in a Greek Clinical Population: A Validation Study. Open Journal of Medical Psychology, 7, 59-81.

https://doi.org/10.4236/ojmp.2018.74006

Received: June 18, 2018

Accepted: July 31, 2018

Published: August 3, 2018

Copyright (c) 2018 by authors and Scientific Research Publishing Inc. This work is licensed under the Creative Commons Attribution International License (CC BY 4.0).

http://creativecommons.org/licenses/by/4.0/

\begin{abstract}
Client attachment to therapist has been long considered a prominent process variable in psychotherapy research. The purpose of this study was to translate in Greek and evaluate the structure, reliability, convergent and discriminant validity of the well-known and widely administered Client Attachment to Therapist Scale (CATS) with exploratory and confirmatory factor analysis in a clinical sample of 153 clients of different treatment modalities and at different agencies. The results indicated that the EFA resulted in a model almost identical to the Mallinckrodt, Gantt and Coble's [1] original model after the deletion of six items. Moreover, the findings indicated adequate internal consistency, test-retest reliability, convergent and discriminant validity of the three factors. Normalized scores were provided to help mental health professionals interpret the scale scores. In conclusion, CATS is a valid and reliable tool to measure client attachment to therapist, whose use can promote psychotherapeutic process and outcome. Thus, more validation studies should be conducted in several cultural contexts to better understand its structure and psychometric characteristics.
\end{abstract}

\section{Keywords}

Client Attachment to Therapist, Validation, Therapeutic Relationship, Greece

\section{Introduction}

First introduced in Bowlby's attachment theory [2] [3], the "secure base" has become the backbone of the burgeoning attachment-informed psychotherapy research. As it was initially highlighted [4], the role of attachment security in the therapeutic relationship is a key process variable in psychotherapy, since it faci- 
litates exploration of client's painful feelings and troubling material, promoting thus client's insight and new coping abilities [5]. To date, there is a substantial literature showing that the therapist-client relationship contains a number of characteristics akin to those inherent in an attachment tie [6] [7] [8] [9] and that the therapists serve as attachment figures similar to the ones in the client's early childhood [10] [11].

In line with previous research on the child-caregiver relationships [12], Mallinckrodt's work [13] embodied the five key features of the primary secure attachment into the client-therapist relationship. Specifically, a secure client attachment to therapist entails that the latter is perceived as: 1) stronger and wiser, 2) a safe haven in stressful times, 3) a soothing secure base for psychological exploration, while at the same time, the client experiences, 4) a tendency for proximity and emotional connection to the therapist, as well as 5) separation anxiety in the therapist's unavailability or near termination. Along with secure attachment reflecting one's optimal affectional bond with a responsive and trustworthy empathic figure [4], a large body of research has demonstrated that insecure attachment patterns may also develop from differences in consistency of caregivers' responses to one's needs. Ainsworth's cutting-edge laboratory study [14] showed that, depending on whether caregivers respond inconsistently or rather with unresponsiveness and emotional unavailability, anxious-ambivalent and anxious-avoidant attachment patterns may be resulted, respectively.

Elaborating on this work, several studies on adult attachment supported Bowlby's propositions [4] that early attachment models constitute internal representations, or "working models", of self and others, and they are transferred throughout life as prototypes for all intimate relationships, including the developing one between therapist and client. Nevertheless, these studies suggested various assessments of adult attachment, either as a two-dimensional model (i.e. positive vs. negative models of self and others) leading to a four-category interview-based and self-report attachment measures (i.e. secure, preoccupied, dismissing and fearful) [15] [16], or as a three-category self-report measure (i.e. secure, ambivalent, and avoidant attachment) analogous to Ainsworth's classification [17]. Moreover, a large body of research relied on the Adult Attachment Interview (AAI) [18], to classify adult attachment "states of mind" via the analysis of narratives regarding adults' memories of childhood experiences. In any case, research involving the psychotherapy relationship and outcome mainly adopted the self-report tradition of measuring adult attachment [19], and most studies used the Experiences in Close Relationship Scale (ECRS) [20], which introduces a two-dimensional model of attachment, namely anxiety and avoidance.

Following these two attachment dimensions, Mikulincer and Shaver [12] supported previous findings on adult attachment systems by also identifying two main tendencies that someone may exhibit in order to deal with attachment issues: a deactivating and a hyperactivating strategy. These two strategies were 
found to play a major role in the client-therapist relationship [21] [22]. Particularly, when clients employ a deactivating strategy, they tend to adopt downgrading behaviors of each of the five aforementioned secure attachment features, while clients who hyperactivate in the relationship with the therapist tend to exaggerate in expressing the five security attachment core elements [13].

Guided by the tripartite typology of attachment in Ainsworth's work, the self-report Client Attachment to Therapist Scale (CATS) was developed by Mallinckrodt, Gantt and Coble [1] to conceptualize the therapeutic relationship from an attachment perspective and to assess the quality of the client attachment to therapist. By using a rational-empirical approach to construct the CATS [23], a panel of nine therapists generated theoretically-driven items, which were then tested to 138 clients having completed at least 5 sessions of counselling. The exploratory factor analytic strategy indicated three CATS subscales, the Secure (14 items), the Preoccupied-Merger (10 items) and the Avoidant-Fearful (12 items), as three distinct patterns in psychotherapy attachment. What is perhaps striking is that the CATS attachment facets well-reflect the later developed two-dimensional models of adult insecure attachment involving anxiety and avoidance [20], but also the hyperactivating and deactivating attachment tendencies [12].

Hence, clients with a Secure attachment perceive their therapists as emotionally responsive and reliable as well as "a secure base" from which to explore threatening psychological territory (e.g." "My counselor is sensitive to my needs", "My counselor helps me look closely at the frightening or troubling things that have happened to me"). In contrast, clients with an Avoidant-Fearful attachment pattern express mistrust, fear of rejection, avoidance of self-disclosure, and the lowest levels of therapeutic alliance (e.g., "It's hard for me to trust my counselor", "Talking over my problems with my counselor makes me feel ashamed or foolish"). Clients with a Preoccupied-Merger attachment wish to blur the boundaries of therapy, long for a close proximity with the therapist (e.g., "I wish my counselor could be with me on a daily basis", "I yearn to be 'at one' with my counselor"), and although they easily develop therapeutic alliance in terms of bonding, this is not the case with regard to the goals and the tasks of therapy. Cluster analysis of the CATS identified one further pattern of attachment in psychotherapy, which was labelled as Reluctant. Clients with a reluctant attachment show unwillingness to self-exploration, albeit their good therapeutic alliance and the positive regard of the therapist [1]. Moreover, current research demonstrated two subtypes of clients based on a combination of CATS subscales, including "pseudosecure" clients having high CATS Secure and high CATS Preoccupied scores, and "individuated-secure" clients having high CATS Secure and low Preoccupied scores [24].

Regarding the psychometric properties of the original CATS, the internal consistency and the retest reliability coefficients in an average of 3.24 weeks after the first measurement were found to be greater than 0.63 for all of the subscales. As regards subscales' intercorrelations, negative associations were found between 
the Secure and the Avoidant-Fearful subscales, while positive ones were found between the Secure and the Preoccupied-Merger subscales. Additionally, concurrent validity was indicated through significant positive associations between the secure subscale and social competencies (i.e. free of object-relations deficits) as well as working alliance. In contrast, the Avoidant-Fearful and the Preoccupied-Merger subscales were negatively correlated with object-relations, working-alliance and self-efficacy constructs [1]. Although the CATS has prevailed mainly as a continuous measure of psychotherapy attachment behavior, its use as a categorization tool to typologize clients across dimensions of attachment patterns in therapy was highlighted as a need for further research [23].

The CATS has been so far the most well-known and widely administered self-report measure of client attachment. According to a recent meta-analysis [19], the original article introducing the CATS [1] has been cited more than 100 times to date. Other relevant instruments include the 45-item self-report Components of Attachment Questionnaire (CAQ) [25] with nine theoretically derived components of psychotherapy attachment, which however was only applied in a psychoanalytic study to assess whether therapists function as attachment figures [11]. On the other hand, the recently developed Patient Attachment to Therapist Rating Scale (PAT-RS) [26] and the Patient Attachment Coding System (PACS) [27] are both promising measures for assessing the quality of attachment to therapist, yet the first one is an observer-rated interview-based instrument and the second one is a transcript-based instrument that is proposed as an alternative to the AAI in psychotherapy research. Finally, the Attachment Avoidance in Therapy Scale (AATS) [28] that measures patient-therapist attachment avoidance portrayed reliability in its all six scales, albeit therapeutic attachment anxiety showed no adequate validity scores.

Findings based on CATS suggest that the client attachment is a prominent variable in treatment [29] since whether a client would be securely, or insecurely, attached to the therapist raises many challenges in the clinical work and influences client change [13]. In the meta-analysis of Mallinckrodt and Jeong [13], the CATS was found to be significantly associated with working alliance and pretherapy adult attachment. Several other studies showed that clients' attachments influence in-session exploration [30] [31] [32], self-disclosure [33], transference [21] [34], the working alliance [35] [36] [37] [38] and therapeutic outcome [39] [40] [41]. Additionally, evidence on the attachment relationship and the real relationship indicated that clients' secure attachment positively correlated with the client-rated real therapeutic relationship [42] [43] as well as with the clients' perceptions of the therapists' empathy [42].

Given the importance of the client attachment to therapist as measured by the CATS as well as the contention that there may be a strong cultural basis on how secure attachment is perceived [44], the aim of this study was to validate the CATS in the Greek context and explore its psychometric properties among a clinical Greek population. More specifically, the objectives of this study were the 
following: 1) to follow a thorough translation process to adapt CATS in Greek; 2) to establish the construct validity of the Client Attachment to Therapist, Greek Version through both exploratory and confirmatory factorial analysis; 3) to study the internal consistency reliability, and test-retest reliability of scale's factors; 4) to examine mean differences of CATS factors across gender and age; 5) to evaluate the convergent and discriminant validity of the CATS with other constructs; and 6) to compute the normalized scores for the Greek client population.

\section{Method}

\subsection{Participants}

One hundred and fifty-three clients, who had completed at least five sessions at the point of the survey (2016-2017), participated in this study. All of the clients were community residents of the wider area of Athens and they were receiving individual psychotherapy or counselling. Of them, 62 clients (40.5\%) were from a community mental health centre, 41 clients (26.8\%) from a non-governmental counselling agency, 19 clients (12.4\%) from a training humanistic psychotherapy centre, and 31 clients (20.3\%) from private practice. The compliance rate in the two community treatment agencies was estimated to be around $75 \%$ of the total number of clients invited to participate in the study. The main therapeutic approaches, including psychodynamic, humanistic, systemic, person-centred and cognitive-behavioral, were represented in the joining treatment settings. To participate in the study, the clients should not have sought treatment due to major psychopathology. Specifically, $35.7 \%$ of the clients requested therapy for life problems, $24.4 \%$ for emotional disorders, while $20.3 \%$ and $19.6 \%$ for anxiety and phobic disorders, respectively.

The sample consisted of 37 (24\%) men and 116 (76\%) women. The majority of the clients (37.9\%) were aged between 26 - 35 years old, following by those aged between $36-45$ and 46 - 55 years old ( $23.2 \%$ and $19.1 \%$, respectively). The youngest (18 - 25 years) and the eldest (56 - 65 years) clients were represented in smaller percentages $(17.8 \%$ and $2 \%$, respectively). Regarding their education, most of the participants (42.5\%) were university graduates $(\mathrm{N}=65)$, while $32 \%$ $(\mathrm{N}=49)$ held a master degree. Almost half of them $(51 \%)$ were single $(\mathrm{N}=78)$. The highest percentages of clients $(31.1 \%$ and $24.6 \%$, respectively) worked at the private sector $(\mathrm{N}=19)$, or they were free-lancers $(\mathrm{N}=15)$.

\subsection{Materials}

Client Attachment to Therapist Scale (CATS) [1] is a 36-item self-report measure developed to assess clients' perceptions of the client-therapist relationship from the perspective of attachment theory. Participants respond on a 6-point scale ranging from strongly agree (1) to strongly disagree (6). The scale consisted of three dimensions: 1 ) secure attachment (clients' feeling encouraged to explore frightening or troubling material in therapy and experiencing the therapist as responsive, sensitive, emotionally available, and a comforting pres- 
ence), 2) avoidant-fearful attachment (suspicion that the therapist is disapproving and likely to be rejecting if displeased, reluctance to make personal disclosures, and feeling threatened or humiliated in the sessions), and 3) preoccupied-merger attachment (longing for more contact and to be "at one" with the therapist, wishing to expand the relationship beyond the bounds of therapy, and preoccupation with the therapist and the therapist's other clients). In our sample, the 3 subscales as well as the total score of the scale demonstrated satisfied psychometric properties.

Experiences in Close Relationships-Revised. The Greek Version of the Revised Experiences in Close Relationships (ECR-R) [45] [46] is a 36-item, self-report instrument of adult romantic attachment. The instrument comprises two subscales, 18 items each, which assess attachment anxiety and avoidance. Sample items are " $P \mathrm{~m}$ afraid that I will lose my partner's love" (anxiety subscale) and "I prefer not to show a partner how I feel deep down" (avoidance subscale). Participants indicate their level of agreement to each item on a 7-point Likert-type scale, where $1=$ strongly disagree and $7=$ strongly agree. Instructions for completing the scale read: "Please take a moment to think about your overall experiences in romantic relationships including both your previous and current romantic experiences and answer the following questions".

Working Alliance Inventory. The Working Alliance Inventory (WAI) [47] [48] is a self-report questionnaire with 36 items which measures the strength of the therapeutic alliance during the therapeutic procedure. Each item is rated on a 7 -point Likert scale ( $1=$ Does not correspond at all; $7=$ Corresponds exactly). This scale is available in three forms: one for the therapist, one for the client and one for the independent judge. In the present study, the scale for the client was used. In our sample, the scale demonstrated good internal consistency ( $\alpha=$ 0.96).

Therapeutic Reactance Scale. The Therapeutic Reactance Scale (TRS) [49] is a 28 -item self-report scale and it is used as the measure of psychological reactance, as it is defined by Brehm [50]. This instrument consists of a total score as well as two subscale scores, which are labelled verbal and behavioural reactance. Items on the Therapeutic Reactance Scale tend to include statements regarding verbal and behavioural oppositional behaviour (i.e., "If I am told what to do, I often do the opposite"; "I am relatively opinionated"; and "I usually go along with others' advice"). These are rated on a 4-point Likert Type scale anchored from strongly agree to strongly disagree.

Hope Scale. The Greek version of the Hope Scale (HS) [51] [52] was used to measure individuals' sense of successful goal-directed determination and planning of ways to meet goals using eight items rated on a 4-point Likert scale ranging from "Definitely False" to "Definitely True". In our sample, the scale demonstrated good internal consistency $(\alpha=0.89)$.

\subsection{Procedure}

Regarding the participants from the two treatment agencies, all clients who met 
the inclusion criteria of the study (i.e. older than 18 years, with no major psychopathology, and at least 5 completed sessions) were informed by the researchers about the purpose of the study, as being a validation assessment of a self-administered questionnaire that describes "aspects of the therapeutic relationship". Data were collected by the researchers with the confirmation that participation in the study was voluntary and had no impact on the treatment services received. Participation in the study did not include any incentives. All clients signed a written consent prior to their participation and anonymity was ensured. A subsample of 52 consecutive clients from the community mental health centre provided retest data, labelled with anonymous identifiers, by completing the CATS a month and two months after the initial survey. To ensure homogeneity in the retest process, all clients should have completed 5 - 8 sessions when data collection took place, while in the rest of the sample clients were allowed to participate no matter how many sessions they had completed beyond the fifth session so as to increase variability [1]. With regard to the clients from the training psychotherapy centre, all trainees participated in the study. Clients from the private practice were recruited by post-graduate psychology students who administered the questionnaire to adults of their social environment who underwent psychotherapy. In all cases, the time needed to complete the CATS was estimated to be approximately 15 minutes.

\subsection{Statistical Analysis}

\section{Translation and adaptation into the Greek cultural context}

The forward-backward translation was adopted for the Greek version of the CATS, as it is the most common translation procedure [53]. Specifically, two bilingual independent translators translated the English items to the Greek language (forward translation) and then two other translators translated back the Greek items into the original language (backward translation). Inaccuracies between the two versions were retranslated until full agreement was achieved between the authors and the independent translators (Table 1).

\section{Validation}

Normality testing. Firstly, the distributional indices of the CATS' items were examined. The means, standard errors, standard deviations, variances, skewness and kurtosis indices were computed for the 36 items. Skewness values less than 2 and kurtosis values less than 7 are considered to prove normal distribution [54].

Inter-item correlations. The Pearson $\mathrm{r}$ intercorrelations of the CATS items were computed and values among 0.20 and 0.40 were considered to indicate reasonable item homogeneity, values less than 0.20 to indicate that the items load at different factors and higher than 0.40 to indicate that the items do not capture a big width of the factor variance [55]. In general, correlation over 0.30 was considered as indicative of the factorability of the correlation matrix [56].

Confirmatory factor analysis. A confirmatory factor analysis (CFA) was conducted using the IBM SPSS AMOS, version 21, to test Mallinckrodt, Gantt and 
Table 1. List of CATS items in the original and the Greek version.

Item

Original version

Greek version

1 I don't get enough emotional support from my counselor.

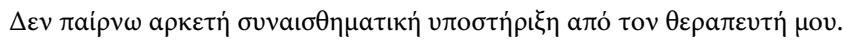

2 My counselor is sensitive to my needs.

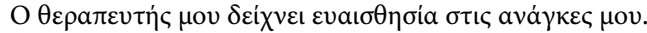

3 I think my counselor disapproves of me.

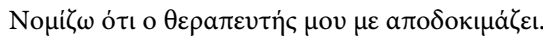

4 I yearn to be "at one" with my counselor.

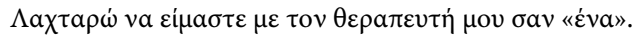

5 My counselor is dependable.

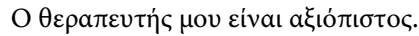

Talking over my problems with my counselor makes me feel ashamed or foolish.

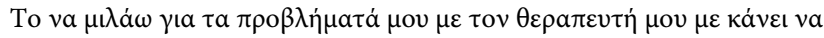

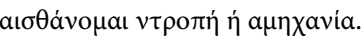

7 I wish my counselor could be with me on a daily basis.

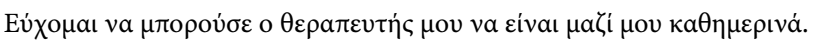

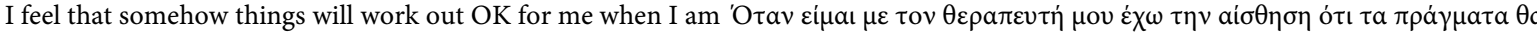
with my counselor.

9 I know I could tell my counselor anything and s/he would not reject me.

10 I would like my counselor to feel closer to me.

11 My counselor isn't giving me enough attention.

12 I don't like to share my feelings with my counselor.

13 I'd like to know more about my counselor as a person.

When I show my feelings, my counselor responds in a helpful way.

15 I feel humiliated in my counseling sessions.

16 I think about calling my counselor at home.

17 I don't know how to expect my counselor to react from session to session.

18

Sometimes I'm afraid that if I don't please my counselor, s/he will reject me.

19 I think about being my counselor's favorite client.

20 I can tell that my counselor enjoys working with me.

21 I suspect my counselor probably isn't honest with me.

I wish there were a way I could spend more time with my counselor.

23

I resent having to handle problems on my own when my counselor could be more helpful.

24 My counselor wants to know more about me than I am comfortable talking about.

25 I wish I could do something for my counselor too.

26 My counselor helps me to look closely at the frightening or troubling things that have happened to me.

27 I feel safe with my counselor.

I wish my counselor were not my counselor so that we could be friends.

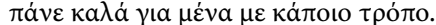

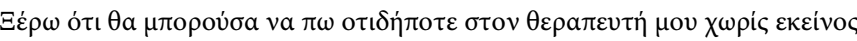
$\nu \alpha \mu \varepsilon \alpha \pi \varepsilon \dot{\varepsilon} \rho \iota \pi \tau$

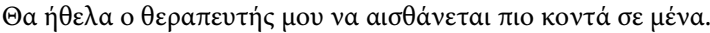

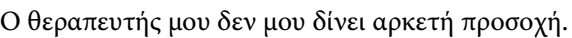

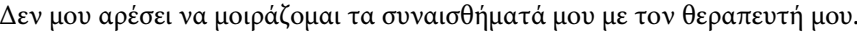

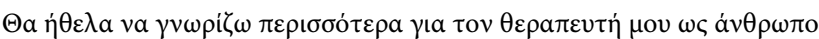

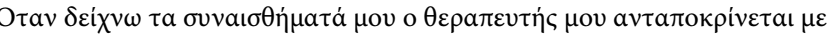

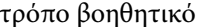

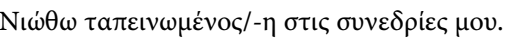

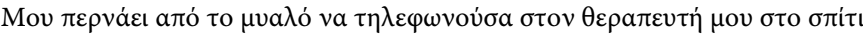
Tov.

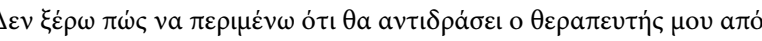

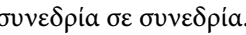

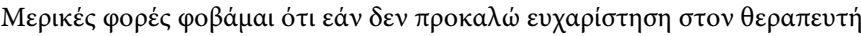
$\mu о v \varepsilon \kappa \varepsilon i v o \varsigma, \theta \alpha \mu \varepsilon$ a

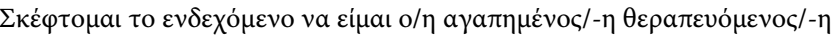

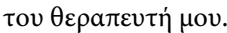

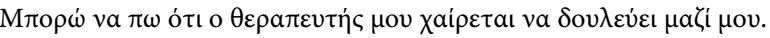

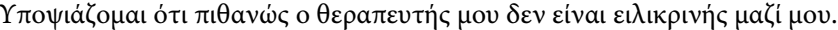

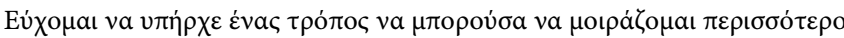

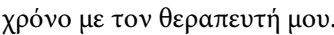

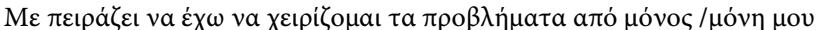

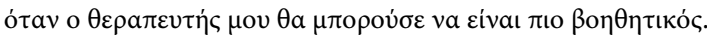

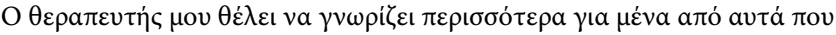
$v \iota \dot{\omega} \theta \omega \dot{\alpha} v \varepsilon \tau \alpha$ va $\pi \omega$.

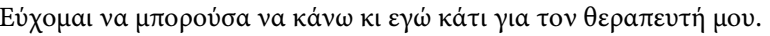

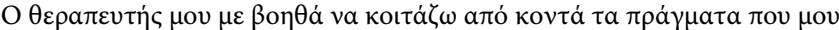

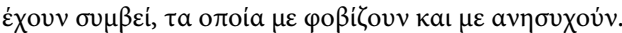

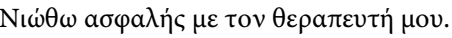

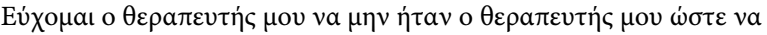

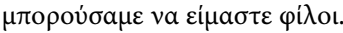




\section{Continued}

29 My counselor is a comforting presence to me when I am upset.

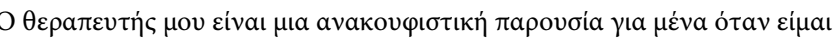
$\alpha v a \sigma \tau \alpha \tau \omega \mu \varepsilon \dot{\varepsilon} \operatorname{cc} /-\eta$.

30 My counselor treats me more like a child than an adult.

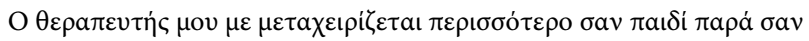
$\varepsilon v \eta \dot{\lambda \iota \kappa a . ~}$

31 I often wonder about my counselor's other clients.

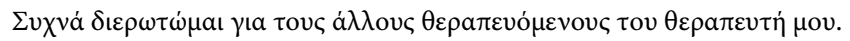
I know my counselor will understand the things that bother me.

33 It's hard for me to trust my counselor.

34 I feel sure that my counselor will be there if I really need her/him.

35

I'm not certain that my counselor is all that concerned about me.

36 When I'm with my counselor, I feel I am his/her highest priority.

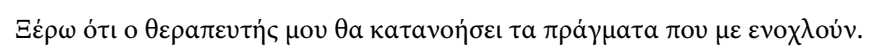

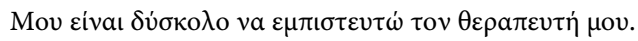

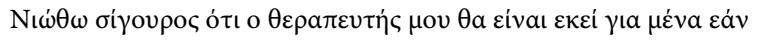

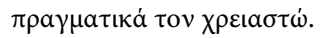

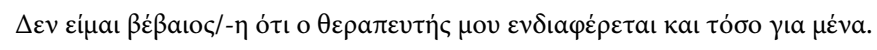

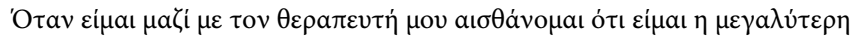

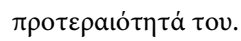

Note. Items 1, 9, 11, 17, 23 and 27 should be reverse keyed. Response anchors and labels are: 1 (Strongly disagree) to 6 (Strongly agree).

Coble's [1] model of three attachment to therapist styles: secure, avoidant-fearful and preoccupied-merger consisting of 14, 12 and 10 items respectively. First of all, Mardia's test of multivariate normality [57] was examined. The value in Mardia's test should be less than $p(p+2)=36(38)=1368(p=$ the number of the items).

In order to assess model fit, several fit indices were evaluated on the basis of the suggestions of $\mathrm{Hu}$ and Bentler [58]: $\mathrm{x}^{2}$ ratio ( $\mathrm{x}^{2} /$ degrees of freedom less than 3), RMSEA [59] and SRMR [58] less than 0.08, CFI [60] and TLI [61] higher than 0.90 .

Exploratory factor analysis. In order to further examine the factorial structure of the CATS, Exploratory Factor Analysis (Principal Axis Factoring) was conducted using the IBM SPSS, version 21, after the testing of the data suitability (sample size higher than 3:1 N:p ratio, KMO index higher than 0.50, and statistically significant Bartlett's Test of Sphericity 0) [56]. Based on the factorial structure of the original version of the test we expected factor loadings on three factors based on the Kaiser's criterion of eigenvalues higher than 1, scree plot and parallel analysis using Monte Carlo PCA for Parallel Analysis.

Internal consistency reliability. Cronbach's alpha and Spearman-Brown prophecy coefficients were evaluated for the CATS factors, where values higher than 0.70 indicate good internal consistency [62] [63].

Test-retest reliability. The consistency and stability of the client's responds were evaluated in three time points, at time 1 after having completed 5 - 8 sessions, a month later (time 2) and then another month later (time 3). Values amongst 0.70 and 0.90 were considered as acceptable [63] [64]. However, in the interpretation of the test-retest reliability values it should be kept in mind the time between tests, the context, the type of the sample and the content of the measured construct [65]. 
Convergent and discriminant validity. To further examine construct validity, the correlations between the scale's factor scores and other measures were examined. Positive correlations with similar constructs would indicate good convergent validity and negative or non-correlations with totally different constructs would indicate good discriminant validity of scale's factors.

Mean differences. Possible differences among gender and age groups in CATS factors were examined.

Norms. Sten scores for the CATS factors were computed using Stanscore 4.

\section{Results}

\section{Normality testing}

The distributional indices for the 36 CATS' were computed (see Table 2). Item means ranged from 1.35 to 5.71 in a 6-point Likert-type scale (1 to 6). Even though skewness and kurtosis values of most items were indicative of a normal distribution, answers on items 3, 5, 9, 11, 15, 21, 30 and 33 were not normally distributed based on Cohen and colleagues' [66] criteria, which means that those items will be possibly deleted during the construction of the CFA model.

\section{Inter-item correlations}

The correlations amongst the 36 CATS' items range from 0.00 to 0.63 (see Table 3). The results indicate that the correlation matrix is factorable, since many correlations are higher than 0.30 , however, a lot of CATS items do not correlate significantly, which shows that possibly some items will be excluded from the factor analysis, since they will not load on any factor.

\section{Confirmatory factor analysis}

Firstly, the three-factor model that was identifiable using AMOS was created. Then the normality of the items was assessed again, and the 8 items mentioned above showed unacceptable values to perform a CFA, thus, they were deleted one at a time, after testing the values again. Also, items 18 and 31 showed unacceptable factor loadings (less than 0.30 ) and they were deleted. Then, the multivariate normality of the CATS items was examined using Mardia's test, whose value was 30.066 , less than 1368 , which means that multinormality was achieved. At that point, the model fit was tested; the extraction method was the maximum likelihood. The evaluation of the model fit indices showed that $\mathrm{x}^{2}$ ratio value was acceptable $(2.35<3)$, however, CFI and TLI values were 0.74 and 0.70 respectively, which is lower than the cut-off value of 0.90 . The same applied for the RMSEA and SRMR values, which were 0.09 and $0.13(>0.08)$. These values are indicative of an unacceptable model fit.

\section{Exploratory factor analysis}

In order to further examine the factorial structure of the CATS, an Exploratory Factor Analysis was performed. First of all, data suitability was tested; Sample size was higher than 3:1 N:p ratio, KMO index was 0.80 (higher than 0.50), and Bartlett's Test of Sphericity was statistically significant $(\mathrm{p}=0.00)$. Then the number of factors was tested. Based on Kaiser's criterion of eigenvalues higher 
Table 2. Distributional indices of the CATS items $(n=153)$.

\begin{tabular}{|c|c|c|c|c|c|c|c|c|}
\hline Item No. & Mean & $S E$ & $S D$ & Var & Minimum & Maximum & Skewness & Kurtosis \\
\hline $1^{\mathrm{R}}$ & 1.98 & 0.10 & 1.29 & 1.65 & 1 & 6 & 1.17 & 0.41 \\
\hline 2 & 5.29 & 0.08 & 0.99 & 0.97 & 1 & 6 & -1.87 & 4.36 \\
\hline 3 & 1.39 & 0.07 & 0.91 & 0.83 & 1 & 6 & 3.09 & 10.40 \\
\hline 4 & 2.61 & 0.14 & 1.75 & 3.07 & 1 & 6 & 0.61 & -1.09 \\
\hline 5 & 5.71 & 0.05 & 0.60 & 0.36 & 1 & 6 & -2.87 & 11.32 \\
\hline 6 & 2.25 & 0.12 & 1.47 & 2.17 & 1 & 6 & 1.02 & -.10 \\
\hline 7 & 2.58 & 0.14 & 1.78 & 3.17 & 1 & 6 & 0.61 & -1.15 \\
\hline 8 & 4.59 & 0.12 & 1.45 & 2.10 & 1 & 6 & -1.05 & 0.44 \\
\hline $9^{R}$ & 5.46 & 0.08 & 0.94 & 0.88 & 1 & 6 & -2.20 & 5.27 \\
\hline 10 & 3.07 & 0.13 & 1.64 & 2.67 & 1 & 6 & 0.18 & -1.16 \\
\hline $11^{\mathrm{R}}$ & 1.44 & 0.08 & 1.02 & 1.04 & 1 & 6 & 2.90 & 8.62 \\
\hline 12 & 1.63 & 0.09 & 1.06 & 1.13 & 1 & 6 & 1.68 & 1.85 \\
\hline 13 & 3.10 & 0.14 & 1.71 & 2.92 & 1 & 6 & 0.25 & -1.24 \\
\hline 14 & 5.39 & 0.07 & 0.87 & 0.75 & 1 & 6 & -1.77 & 4.20 \\
\hline 15 & 1.48 & 0.09 & 1.05 & 1.09 & 1 & 6 & 2.37 & 4.95 \\
\hline 16 & 1.59 & 0.09 & 1.16 & 1.34 & 1 & 6 & 1.97 & 2.98 \\
\hline $17^{\mathrm{R}}$ & 2.11 & 0.12 & 1.47 & 2.15 & 1 & 6 & 1.17 & 0.29 \\
\hline 18 & 1.61 & 0.10 & 1.18 & 1.40 & 1 & 6 & 1.90 & 3.01 \\
\hline 19 & 2.20 & 0.12 & 1.47 & 2.15 & 1 & 6 & 0.76 & -0.88 \\
\hline 20 & 4.35 & 0.10 & 1.28 & 1.64 & 1 & 6 & -0.81 & 0.24 \\
\hline 21 & 1.41 & 0.07 & 0.81 & 0.65 & 1 & 6 & 2.61 & 7.65 \\
\hline 22 & 3.20 & 0.14 & 1.77 & 3.15 & 1 & 6 & 0.09 & -1.39 \\
\hline $23^{\mathrm{R}}$ & 2.36 & 0.12 & 1.51 & 2.28 & 1 & 6 & 0.82 & -0.51 \\
\hline 24 & 2.52 & 0.14 & 1.76 & 3.11 & 1 & 6 & 0.78 & -0.85 \\
\hline 25 & 2.94 & 0.15 & 1.89 & 3.57 & 1 & 6 & 0.37 & 1.41 \\
\hline 26 & 5.41 & 0.07 & 0.87 & 0.76 & 1 & 6 & -1.99 & 5.62 \\
\hline $27^{\mathrm{R}}$ & 5.42 & 0.06 & 0.77 & 0.59 & 1 & 6 & -1.23 & 1.01 \\
\hline 28 & 2.58 & 0.14 & 1.73 & 2.98 & 1 & 6 & 0.72 & -0.82 \\
\hline 29 & 5.18 & 0.09 & 1.13 & 1.27 & 1 & 6 & -1.71 & 3.14 \\
\hline 30 & 1.35 & 0.07 & 0.83 & 0.68 & 1 & 6 & 2.85 & 9.03 \\
\hline 31 & 2.29 & 0.13 & 1.64 & 2.69 & 1 & 6 & 0.90 & -0.68 \\
\hline 32 & 5.33 & 0.07 & 0.92 & 0.84 & 1 & 6 & -1.89 & 4.61 \\
\hline 33 & 1.52 & 0.09 & 1.05 & 1.11 & 1 & 6 & 2.41 & 5.36 \\
\hline 34 & 4.93 & 0.11 & 1.31 & 1.71 & 1 & 6 & -1.39 & 1.37 \\
\hline 35 & 1.88 & 0.11 & 1.31 & 1.71 & 1 & 6 & 1.54 & 1.45 \\
\hline 36 & 4.84 & 0.12 & 1.47 & 2.16 & 1 & 6 & -1.31 & 0.66 \\
\hline
\end{tabular}

Note. $S D=$ standard deviation, $S E=$ standard error of mean, Var $=$ variance, ${ }^{\mathrm{R}}=$ item should be reverse keyed. 


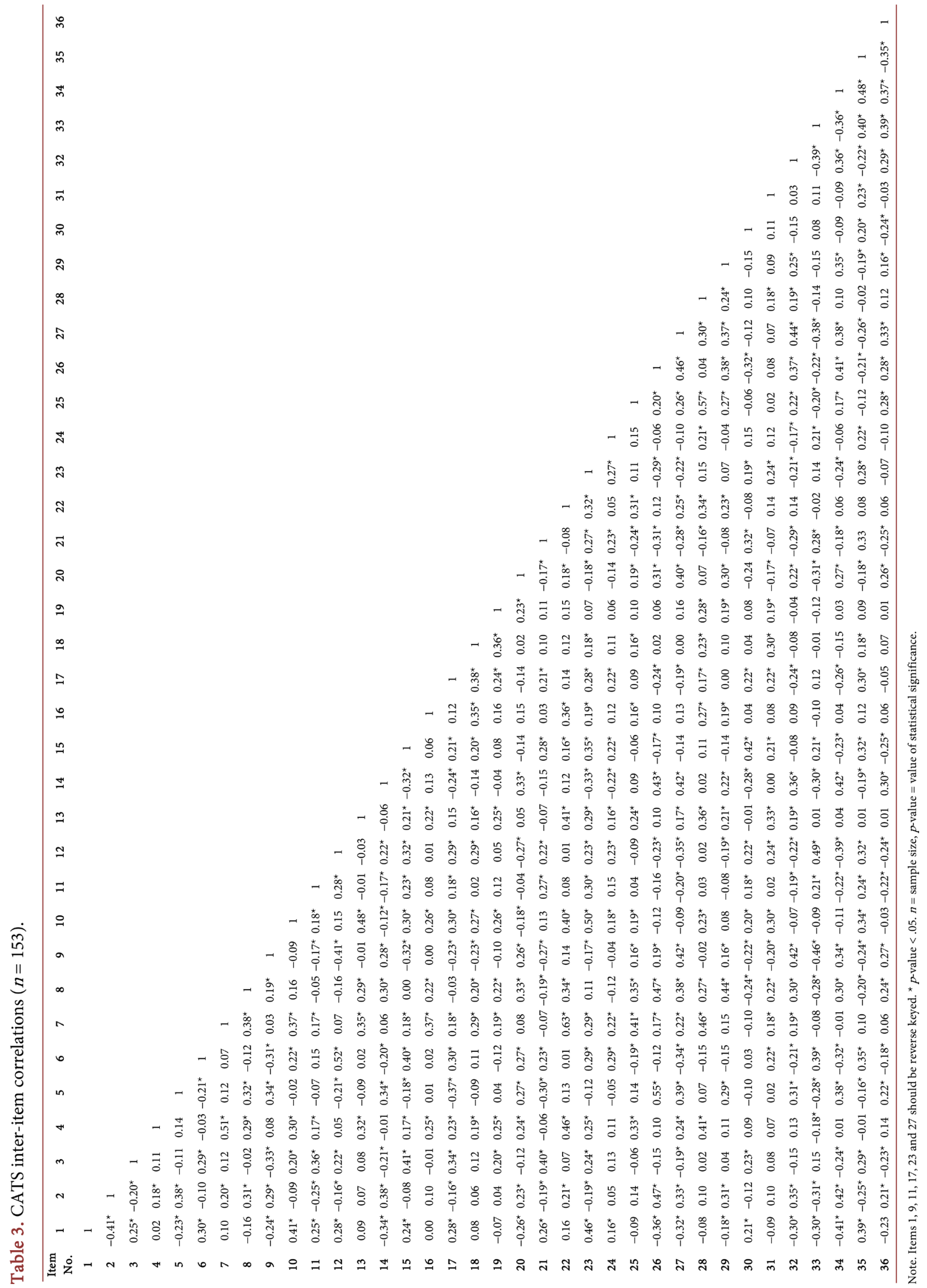


than 1, eight factors showed eigenvalues from 1.027 to 6.165 .

Based on the parallel analysis results, three factors had higher eigenvalues than the random eigenvalues and the same results were visible on the screen test. Also, the same number of factors has been identified by Mallinckrodt and his colleagues [1].

The factor correlation matrix was then examined in order to decide which rotation method to use. According to the results, the three factors showed low to moderate correlations to each other $\left(r_{1,2}=0.21, r_{2,3}=0.16, r_{1,3}=-0.40\right)$, thus an Oblique Rotation Method was used. The initial EFA results showed that items $11,17,24,27,30$, and 36 did not load sufficiently on any factor (loadings lower than 0.30), thus they were deleted.

The results of the Principal Axis Factoring indicate that the three latent variables consisted of 30 items explain $42.43 \%$ of the total variance, which is adequate and shows how much of the variability in the data has been modelled by the extracted factors. More specifically, the first factor consists of eleven items (as depicted by the Secure Attachment to Therapist subscale of the original model), the second of nine items (as depicted by the Preoccupied-Merger Attachment to Therapist subscale of the original model), and the third of ten items (as depicted by the Avoidant-Fearful Attachment to Therapist subscale of the original model). The only divergence in comparison with the original model [1] was that item 31 ("I often wonder about my counselor's other clients.") loads on the Avoidant-Fearful instead of the Preoccupied-Merger attachment style (see Table 4).

\section{Internal consistency reliability}

The Cronbach alpha and Spearman-Brown coefficients were assessed in order to examine the internal consistency of the CATS's subscales. The secure, avoidant-fearful and preoccupied-merger subscales demonstrated good internal consistency. More specifically, their Cronbach alpha values were $0.81,0.77$, and 0.81 , while their Spearman-Brown coefficient values were $0.82,0.70$, and 0.84 , respectively.

\section{Test-retest reliability}

The test-retest reliability assessment showed satisfactory results for the three CATS subscales between the three time points. In particular, the test-retest values among time 1 and times 2 , and 3 for the secure attachment subscale were 0.46 and 0.59 ( $\mathrm{p}<0.001)$, for the avoidant-fearful attachment subscale were 0.67 and $0.75(\mathrm{p}<0.000)$, and for the preoccupied-merger attachment subscale were 0.81 and 0.67 , respectively. Taking into consideration the existence of possible therapeutic change, possible psychopathological symptoms and the content of the "attachment to therapist style" construct, the test-retest results are adequately good.

\section{Convergent and discriminant validity}

To test convergent validity, the correlations between the CATS factors and similar constructs were examined. The results showed that 1) secure attachment subscale positively correlated to working alliance, 2) avoidant-fearful attachment 
Table 4. CATS item loadings per factor.

\begin{tabular}{|c|c|c|c|c|}
\hline Item No. & Item text & Factor 1 & Factor 2 & Factor 3 \\
\hline 26 & $\begin{array}{l}\text { My counselor helps me to look closely at the frightening or troubling things that have } \\
\text { happened to me. }\end{array}$ & 0.83 & & \\
\hline 2 & My counselor is sensitive to my needs. & 0.65 & & \\
\hline 14 & When I show my feelings, my counselor responds in a helpful way. & 0.57 & & \\
\hline $1^{\mathrm{R}}$ & I don't get enough emotional support from my counselor. & 0.57 & & \\
\hline 5 & My counselor is dependable. & 0.52 & & \\
\hline 34 & I feel sure that my counselor will be there if I really need her/him. & 0.49 & & \\
\hline 8 & I feel that somehow things will work out OK for me when I am with my counselor. & 0.48 & 0.41 & \\
\hline 29 & My counselor is a comforting presence to me when I am upset. & 0.42 & & \\
\hline 32 & I know my counselor will understand the things that bother me. & 0.41 & & \\
\hline 20 & I can tell that my counselor enjoys working with me. & 0.31 & & \\
\hline $23^{\mathrm{R}}$ & I resent having to handle problems on my own when my counselor could be more helpful. & 0.37 & -0.51 & \\
\hline 7 & I wish my counselor could be with me on a daily basis. & & 0.72 & \\
\hline 22 & I wish there were a way I could spend more time with my counselor. & & 0.69 & \\
\hline 4 & I yearn to be "at one" with my counselor. & & 0.64 & \\
\hline 28 & I wish my counselor were not my counselor so that we could be friends. & & 0.63 & \\
\hline 10 & I would like my counselor to feel closer to me. & & 0.60 & \\
\hline 25 & I wish I could do something for my counselor too. & & 0.56 & \\
\hline 13 & I'd like to know more about my counselor as a person. & & 0.56 & \\
\hline 16 & I think about calling my counselor at home. & & 0.42 & \\
\hline 19 & I think about being my counselor's favorite client. & & 0.32 & \\
\hline 6 & Talking over my problems with my counselor makes me feel ashamed or foolish. & & & 0.66 \\
\hline 12 & I don't like to share my feelings with my counselor. & & & 0.63 \\
\hline $9^{\mathrm{R}}$ & I know I could tell my counselor anything and s/he would not reject me. & & & 0.54 \\
\hline 33 & It's hard for me to trust my counselor. & & & 0.51 \\
\hline 31 & I often wonder about my counselor's other clients. & & & 0.50 \\
\hline 35 & I'm not certain that my counselor is all that concerned about me. & & & 0.47 \\
\hline 15 & I feel humiliated in my counseling sessions. & & & 0.46 \\
\hline 3 & I think my counselor disapproves of me. & & & 0.39 \\
\hline 21 & I suspect my counselor probably isn't honest with me. & & & 0.37 \\
\hline 18 & Sometimes I'm afraid that if I don't please my counselor, s/he will reject me. & & 0.31 & 0.34 \\
\hline \multicolumn{2}{|l|}{ Eigenvalues } & 6.165 & 4.794 & 1.770 \\
\hline \multicolumn{2}{|c|}{ Variance explained } & $20.55 \%$ & $15.98 \%$ & $5.90 \%$ \\
\hline \multicolumn{2}{|c|}{ Total variance explained } & $42.43 \%$ & & \\
\hline
\end{tabular}

Note. Items 1, 9 and 23 have been reverse keyed. Extraction method: Principal Axis Factoring. Rotation method: Oblimin. 
Table 5. Convergent and discriminant validity: Average correlations of CATS factors with other constructs.

\begin{tabular}{ccccc}
\hline & $\boldsymbol{n}$ & S & A-F & P-M \\
\hline Secure Attachment & 153 & 1 & & \\
Avoidant-Fearful Attachment & 153 & $-0.49^{* *}$ & 1 & \\
Preoccupied-Merger Attachment & 153 & 0.16 & 0.16 & 1 \\
Hope & 91 & 0.20 & -0.08 & -0.04 \\
Working Alliance & 142 & $0.82^{* *}$ & $-0.55^{* *}$ & 0.07 \\
Anxiety in Close Relationships & 89 & -0.02 & $0.25^{*}$ & $0.34^{* *}$ \\
Avoidance in Close Relationships & 89 & -0.14 & $0.33^{* *}$ & 0.14 \\
Therapeutic Reactance & 52 & -0.01 & 0.22 & 0.23 \\
\hline
\end{tabular}

Note. $\mathrm{S}=$ secure attachment to therapist subscale, A-F = avoidant-fearful attachment to therapist subscale, $\mathrm{P}-\mathrm{M}=$ preoccupied-merger attachment to therapist subscale. ${ }^{* *} \mathrm{p}$-value $<0.01,{ }^{*} \mathrm{p}$-value $<0.05 . n=$ sample size, $\mathrm{p}$-value $=$ value of statistical significance.

subscale was positively correlated to anxiety and avoidance in close relationships, and 3) preoccupied-merger attachment subscale positively correlated to anxiety in close relationships. Furthermore, the results of the discriminant validity testing showed that 1 ) secure attachment subscale negatively correlated to avoidant-fearful attachment subscale, 2) avoidant-fearful attachment subscale was negatively correlated to working alliance, 3) preoccupied-merger attachment subscale was not correlated with other attachment styles and avoidance in close relationships, and 4) all three subscales were not correlated to therapeutic reactance and hope levels (see Table 5).

\section{Mean differences}

The mean differences among the subgroups created by gender and age were examined and the results indicated that there were no statistically significant differences across the different groups (see Table 6).

\section{Norms}

To help psychotherapists and counsellors interpret the scores of the three subscales, the raw scores were converted to normalized scores (sten scores; ranging from 1 to 10 ; see Table 7).

\section{Discussion}

The main aim of this study was to examine the psychological properties of the CATS, which is a measure that assesses the client-therapist relationship from the perspective of attachment theory, in a clinical Greek population. More specifically, the objectives of this study were to establish the construct validity of the Client Attachment to Therapist, to study the internal consistency reliability, and construct reliability, to examine mean differences of CATS factors across gender and age and to evaluate the convergent and discriminant validity of the CATS with other constructs.

Firstly, forward-backward translation and bilingual participants verified, 
Table 6. Mean differences (means and standard deviations) of CATS factors by demographics.

\begin{tabular}{cccc}
\hline & S & A-F & P-M \\
\hline $\begin{array}{c}\text { Total sample } \\
\text { Gender }\end{array}$ & $55.85(7.31)$ & $17.01(6.66)$ & $23.87(9.51)$ \\
Male & & & \\
Female & $54.27(7.20)$ & $17.19(6.79)$ & $24.92(10.33)$ \\
$t$ & $56.35(7.31)$ & $16.94(6.64)$ & $23.53(9.25)$ \\
$d f$ & -1.51 & 0.19 & 0.77 \\
Age groups & 151 & 151 & 151 \\
$18-25$ & & $17.78(6.89)$ & $22.78(8.39)$ \\
$26-35$ & $55.74(6.26)$ & $17.81(5.86)$ & $22.64(9.89)$ \\
$36-45$ & $54.83(7.17)$ & $15.54(6.24)$ & $24.08(7.64)$ \\
$46-55$ & $58.11(6.78)$ & $16.96(8.47)$ & $26.06(10.84)$ \\
$56-65$ & $54.86(8.95)$ & $13.67(3.21)$ & $37.33(8.08)$ \\
$F$ & $56.33(1.15)$ & .91 & 2.31 \\
$d f$ & 1.27 & $4 / 147$ & $4 / 147$ \\
\hline
\end{tabular}

Note. $\mathrm{S}=$ secure attachment to therapist subscale, A-F = avoidant-fearful attachment to therapist subscale, $\mathrm{P}-\mathrm{M}=$ preoccupied-merger attachment to therapist subscale. There are no significant differences. $t=$ $\mathrm{t}$-statistic in independent samples t-test, $F=\mathrm{F}$-statistic in one-way analysis of variance (ANOVA), $d f=\mathrm{de}-$ grees of freedom.

Table 7. Norms for the CATS factors

\begin{tabular}{cccc}
\hline S & \multicolumn{2}{c}{ Raw score range } & Sten equivalent \\
\cline { 2 - 3 } 11 to 38 & A-F & P-M & 1 \\
39 to 44 & 9 & 10 & 2 \\
45 to 47 & 10 & 11 to 13 & 3 \\
48 to 53 & 12 & 14 to 18 & 4 \\
54 to 56 & 13 to 15 & 19 to 22 & 5 \\
57 to 60 & 16 to 18 & 23 to 27 & 7 \\
61 to 63 & 19 to 23 & 28 to 34 & 8 \\
64 & 24 to 28 & 35 to 39 & 9 \\
65 & 29 to 35 & 40 to 42 & 10 \\
66 & 36 to 54 & 43 to 60 & 5 \\
\hline
\end{tabular}

Note. $\mathrm{S}=$ secure attachment to therapist subscale, A-F = avoidant-fearful attachment to therapist subscale, $\mathrm{P}-\mathrm{M}=$ preoccupied-merger attachment to therapist subscale.

through test-retest (and high correlations), that the translated version was equivalent to the original one. Secondly, even though the confirmatory factor analysis does not confirm the theoretical model of the three factors suggested by 
Mallinckrodt, Gantt and Coble [1], the exploratory factor analysis results in the same model after the deletion of six items that do not load on any factor (q11, q24, q30, q17, q36, q27). Also, one item (q31) loads on factor Avoidant-Fearful instead of Preoccupied-Merger type, as suggested by the authors of the original version. Test-retest reliability of the three factors is satisfactory and confirms the consistency of the Greek version and construct validity and item-total correlations supported the strength of the Greek scale and alignment to the original English version. Internal consistency showed high alpha coefficients, which indicate good internal consistency [62] [63].

To further examine construct validity, the correlations between scale's factor scores and other measures were studied. The results indicated that there is a positive correlation between Secure Attachment and Working Alliance which is in accordance with a previous study [19]. In addition, there is a positive relationship between Avoidant-Fearful Attachment and Avoidance as well as a positive relationship between Avoidant-Fearful Attachment and Anxiety in Close Relationships' Attachment. Finally, yet importantly, a positive correlation between Preoccupied-Merger Attachment and Anxiety in Close Relationships' Attachment was found. A number of recent studies have linked attachment avoidance and anxiety to distinct profiles of psychological distress and maladaptive interpersonal functioning [67], perfectionism [68] and social competencies [69].

Furthermore, the results showed that secure attachment subscale negatively correlated to avoidant-fearful attachment subscale and avoidant-fearful attachment subscale was negatively correlated to working alliance. These results are in accordance with other studies [19] [42] [43]. Preoccupied-merger attachment subscale was not correlated with other attachment styles and avoidance in close relationships. Finally, all three subscales were not correlated to therapeutic reactance and hope levels. Some studies have indicated that many attachment associated outcomes are linked to the hope construct [70] [71] [72] but further research should be conducted in order to examine this relationship.

The strength of this paper rests on the lack of studies in Greece regarding client-therapist relationship because of the absence of a valid and reliable instrument as well to the statistical analysis that were used. As with all research, the present paper has a few limitations worth considering. Limitations of this study include those inherent to self-report measures as well as the relatively small samples used for analyses. Research with larger and more diverse samples should further identify the strengths and weakness of the CATS, as well as its predictive ability of outcome.

Further research is needed to test the psychometric properties of the CATS with other samples of population. Having established the CATS as a valid and reliable measure in the Greek cultural context, a number of interesting directions for further research would be opened. In particular, the CATS could be administered to assess the therapeutic relationship in specific populations in relation to their needs and attitudes towards counselling and psychotherapy services. For 
example, relevant studies in the Greek cultural context have shown that Greek university students held a negative attitude towards visiting a university psychotherapy centre [73], despite the beneficial effects of psychological services in students' anxiety and depression levels as well as their self-esteem [74]. Moreover, the existing needs of the Greek population for therapeutic services may have differentiated due to the recent global economic crisis [75] [76]. Such an issue requires further investigation in relation to the role of the therapeutic relationship, so as to tailor the mental health services to adequately address the emerging needs. Overall, the use of the CATS is expected to shed light on major dimensions of the therapeutic relationship and the therapeutic process generally, an under-examined research subject so far in the Greek context. Finally, cross cultural studies would add strength to the research area of clinical psychology and psychotherapy.

\section{Conclusion}

The study provides useful information regarding the use of the CATS in future studies in Greek speaking populations and it could expand psychology research. Although more research is needed, the results of this study show that CATS is a valid and reliable instrument for measuring client attachment in the Greek cultural context, with good psychometric strength. Future research regarding the validation of the CATS in the Greek population could focus on more specific psychology measures while also exploring the cultural differences between different populations regarding clients' therapeutic attachment to the therapist.

\section{Conflicts of Interest}

The authors declare no conflicts of interest regarding the publication of this paper.

\section{References}

[1] Mallinckrodt, B., Gantt, D.L. and Coble, H.M. (1995) Attachment Patterns in the Psychotherapy Relationship: Development of the Client Attachment to Therapist Scale. Journal of Counseling Psychology, 42, 307-317. https://doi.org/10.1037/0022-0167.42.3.307

[2] Bowlby, J. (1969) Attachment and Loss: Vol. 1 Attachment. Basic Books, New York.

[3] Bowlby, J. (1980) Attachment and Loss: Vol. 3 Loss. Basic Books, New York.

[4] Bowlby, J. (1988) A Secure Base. Basic Books, New York.

[5] Wallin, D.J. (2007) Attachment in Psychotherapy. Guilford Press, New York.

[6] Farber, B.A., Lippert, R.A. and Nevas, D.B. (1995) The Therapist as Attachment Figure. Psychotherapy, 32, 204-212. https://doi.org/10.1037/0033-3204.32.2.204

[7] Obegi, J. (2008) The Development of the Client-Therapist Bond through the Lens of Attachment Theory. Psychotherapy. Theory, Research, Practice, Training, 45, 431-446. https://doi.org/10.1037/a0014330

[8] Shane, M.G. and Shane, M. (2001) The Attachment Motivational System as a Guide to an Effective Therapeutic Process. Psychoanalytic Inquiry, 21, 675-687. 
https://doi.org/10.1080/07351692109348967

[9] Skourteli, M.C. and Lennie, C. (2011) The Therapeutic Relationship from an Attachment Theory Perspective. Counselling Psychology Review, 26, 20-33.

[10] Daly, K.D. and Mallinckrodt, B. (2009) Expert Therapists' Approaches to Psychotherapy with Adult Clients Who Present with Attachment Avoidance or Anxiety. Journal of Counseling Psychology, 56, 549-563. https://doi.org/10.1037/a0016695

[11] Parish, M. and Eagle, M.N. (2003) Attachment to the Therapist. Psychoanalytic Psychology, 20, 271-286. https://doi.org/10.1037/0736-9735.20.2.271

[12] Mikulincer, M. and Shaver, P.R. (2007) Attachment in Adulthood: Structure, Dynamics, and Change. Guilford Press, New York, NY.

[13] Mallinckrodt, B. (2010) The Psychotherapy Relationship as Attachment: Evidence and Implications. Journal of Social and Personal Relationships, 27, 262-270. https://doi.org/10.1177/0265407509360905

[14] Ainsworth, M.D.S., Blehar, M.C., Waters, E. and Wall, S. (1978) Patterns of Attachment: A Psychological Study of the Strange Situation. Erlbaum, Hillsdale, NJ.

[15] Bartholomew, K. and Horowitz, L.M. (1991) Attachment Styles among Young Adults: A Test of a Four-Category Model. Journal of Personality and Social Psychology, 61, 226-244. https://doi.org/10.1037/0022-3514.61.2.226

[16] Griffin, D. and Bartholomew, K. (1994) Models of the Self and Other: Fundamental Dimensions Underlying Measures of Adult Attachment. Journal of Personality and Social Psychology, 67, 430-445. https://doi.org/10.1037/0022-3514.67.3.430

[17] Hazan, C. and Shaver, P.R. (1987) Romantic Love Conceptualized as an Attachment Process. Journal of Personality and Social Psychology, 52, 511-524. https://doi.org/10.1037/0022-3514.52.3.511

[18] Main, M. and Goldwyn, R. (1998) Adult Attachment Scoring and Classification Systems. University of California, Berkeley.

[19] Mallinckrodt, B. and Jeong, J. (2015) Meta-Analysis of Client Attachment to Therapist: Associations with Working Alliance and Client Pretherapy Attachment. Psychotherapy, 52, 134-139. https://doi.org/10.1037/a0036890

[20] Brennan, K.A., Clark, C.L. and Shaver, P.R. (1998) Self-Report Measurement of Adult Attachment: An Integrative Overview. In: Simpson, J.A. and Rholes, W.S., Eds., Attachment Theory and Close Relationships, Guilford Press, New York, 46-76.

[21] Mallinckrodt, B. and Chen, E.C. (2004) Attachment and Interpersonal Impact Perceptions of Group Members: A Social Relations Model Analysis of Transference. Psychotherapy Research, 14, 210-230. https://doi.org/10.1093/ptr/kph018

[22] Mallinckrodt, B., Choi, G. and Daly, K.D. (2014) Pilot Test of a Measure to Assess Therapeutic Distance and Its Association with Client Attachment and Corrective Experience in Therapy. Psychotherapy Research, 25, 505-517. https://doi.org/10.1080/10503307.2014.928755

[23] Robbins, S.B. (1995) Attachment Perspectives on the Counseling Relationship: Comment on Mallinckrodt, Gantt, and Coble. Journal of Counseling Psychology, 42, 318-319. https://doi.org/10.1037/0022-0167.42.3.318

[24] Mallinckrodt, B., Anderson, M.Z., Choi, G., Levy, K.N., Petrowski, K., Sauer, E.M., Tishby, O. and Wiseman, H. (2017) Pseudosecure vs. Individuated-Secure Client Attachment to Therapist: Implications for Therapy Process and Outcome. Psychotherapy Research, 27, 677-691. https://doi.org/10.1080/10503307.2016.1152411

[25] Parish, M. (2000) The Nature of the Patient's Tie to the Therapist (Doctoral Dissertation, Adelphi University, 1999). Dissertation Abstracts International, 60, 6378-B. 
[26] Lilliengren, P., Werbart, A., Mothander, P.R., Ekström, A., Sjögren, S. and Ögren M.L. (2013) Patient Attachment to Therapist Rating Scale: Development and Psychometric Properties. Psychotherapy Research, 24, 184-201. https://doi.org/10.1080/10503307.2013.867462

[27] Talia, A., Miller-Bottome, M. and Daniel, S.I. (2017) Assessing Attachment in Psychotherapy: Validation of the Patient Attachment Coding System (PACS). Clinical Psychology and Psychotherapy, 24, 149-161. https://doi.org/10.1002/cpp.1990

[28] Láng, A., Péleya, B., Barlaya, L.M. and Bernáth, L. (2012) Measuring Patients' Attachment Avoidance in Psychotherapy: Development of the Attachment Avoidance in Therapy Scale (AATS). Europe's Journal of Psychology, 8, 620-631. https://doi.org/10.5964/ejop.v8i4.485

[29] Daniel, S.I.F. (2006) Adult Attachment Patterns and Individual Psychotherapy: A Review. Clinical Psychology Review, 26, 968-984.

https://doi.org/10.1016/j.cpr.2006.02.001

[30] Mallinckrodt, B., Porter, M.J. and Kivlighan, D.M. (2005) Client Attachment to Therapist, Depth of In-Session Exploration and Object Relations in Brief Psychotherapy. Psychotherapy: Theory, Research, Practice, Training, 42, 85-100. https://doi.org/10.1037/0033-3204.42.1.85

[31] Romano, V., Fitzpatrick, M. and Janzen, J. (2008) The Secure-Base Hypothesis: Global Attachment, Attachment to Counselor, and Session Exploration in Psychotherapy. Journal of Counseling Psychology, 55, 495-504. https://doi.org/10.1037/a0013721

[32] Janzen, J., Fitzpatrick, M. and Drapeau, M. (2008) Processes Involved in Client-Nominated Relationship Building Incidents: Client Attachment, Attachment to Therapist, and Session Impact. Psychotherapy, 45, 377-390. https://doi.org/10.1037/a0013310

[33] Saypol, E. and Farber, B.A. (2010) Attachment Style and Patient Disclosure in Psychotherapy. Psychotherapy Research, 20, 462-471. https://doi.org/10.1080/10503301003796821

[34] Woodhouse, S.S., Schlosser, L.Z., Crook, R.E., Ligiéro, D.P. and Gelso, C.J. (2003) Client Attachment to Therapist: Relations to Transference and Client Recollections of Parental Caregiving. Journal of Counseling Psychology, 50, 395-408. https://doi.org/10.1037/0022-0167.50.4.395

[35] Bachelor, A., Meunier, G., Laverdiére, O. and Gamache, D. (2010) Client Attachment to Therapist: Relation to Client Personality and Symptomatology, and Their Contributions to the Therapeutic Alliance. Psychotherapy. Theory, Research, Practice, Training, 47, 454-468. https://doi.org/10.1037/a0022079

[36] Crook, R.E., Gelso, C.J., Fischer, L. and Silva, L.R. (2007) Therapist Attachment, Client Attachment to Therapist, and Expected Working Alliance: An Analogue Study. Issues in Religion and Psychotherapy, 31, 36-45.

[37] Diener, M.J. and Monroe, J.M. (2011) The Relationship between Adult Attachment Style and Therapeutic Alliance in Individual Psychotherapy: A Meta-Analytic Review. Psychotherapy, 48, 237-248. https://doi.org/10.1037/a0022425

[38] Taylor, P.J., Rietzschel, J., Danquah, A. and Berry, K. (2015) The Role of Attachment Style, Attachment to Therapist, and Working Alliance in Response to Psychological Therapy. Psychology and Psychotherapy. Theory, Research and Practice, 88, 240-253. https://doi.org/10.1111/papt.12045

[39] Meyer, B. and Pilkonis, P.A. (2001) Attachment Style. Psychotherapy, 38, 466-472. https://doi.org/10.1037/0033-3204.38.4.466 
[40] Sauer, E.M., Anderson, M.Z., Gormley, B., Richmond, C.J. and Preacco, L. (2010) Client Attachment Orientations, Working Alliances, and Responses to Therapy: A Psychology Training Clinic Study. Psychotherapy Research, 20, 702-711. https://doi.org/10.1080/10503307.2010.518635

[41] Wiseman, H. and Tishby, O. (2015) Client Attachment, Attachment to the Therapist and Client-Therapist Attachment Match: How Do They Relate to Change in Psychodynamic Psychotherapy? Psychotherapy Research, 24, 392-406. https://doi.org/10.1080/10503307.2014.892646

[42] Fuertes, J.N., Mislowack, A., Brown, S., Gur-Arie, S., Wilkinson, S. and Gelso, C.J. (2007) Correlates of the Real Relationship in Psychotherapy: A Study of Dyads. Psychotherapy Research, 17, 423-430. https://doi.org/10.1080/10503300600789189

[43] Moore, S.R. and Gelso, C.J. (2011) Recollections of a Secure Base in Psychotherapy: Considerations of the Real Relationship. Psychotherapy, 48, 368-373. https://doi.org/10.1037/a0022421

[44] Wang, C.C. and Mallinckrodt, B. (2006) Differences between Taiwanese and U.S. Cultural Beliefs about Ideal Adult Attachment. Journal of Counseling Psychology, 53, 192-204. https://doi.org/10.1037/0022-0167.53.2.192

[45] Fraley, R.C., Waller, N.G. and Brennan, K.A. (2000) An Item Response Theory Analysis of Self-Report Measures of Adult Attachment. Journal of Personality and Social Psychology, 78, 350-365. https://doi.org/10.1037/0022-3514.78.2.350

[46] Tsagarakis, M., Kafetsios, K. and Stalikas, A. (2007) Reliability and Validity of the Greek Version of the Revised Experiences in Close Relationships Measure of Adult Attachment. European Journal of Psychological Assessment, 23, 47-55. https://doi.org/10.1027/1015-5759.23.1.47

[47] Horvath, A.O. and Greenberg, L.S. (1989) Development and Validation of the Working Alliance Inventory. Journal of Counseling Psychology, 36, 223-233. https://doi.org/10.1037/0022-0167.36.2.223

[48] Papadimitriou, G. and Papakostas, I. (2002) The Relationship between the Patient and the Doctor. Medicine, 85, 44-56.

[49] Dowd, E.T., Milne, C.R. and Wise, S.L. (1991) The Therapeutic Reactance Scale: A Measure of Psychological Reactance. Journal of Counseling and Development, 69, 541-545. https://doi.org/10.1002/j.1556-6676.1991.tb02638.x

[50] Brehm, J.W. (1966) A Theory of Psychological Reactance. Academic Press, Oxford.

[51] Snyder, C.R., Harris, C., Anderson, J.R., Holleran, S.A., Irving, L.M., Sigmon, S.T., Harney, P., et al. (1991) The Will and the Ways: Development and Validation of an Individual-Differences Measure of Hope. Journal of Personality and Social Psychology, 60, 570. https://doi.org/10.1037/0022-3514.60.4.570

[52] Moustaki, M. and Stalikas, A. (2012a) The Hope Scale (HS). In: Stalikas, A., Triliva, S. and Roussi, P., Eds., Psychometric Instruments in Greece, 2nd Edition, Pedio, Athens, 517.

[53] Pezirkianidis, C., Karakasidou, E., Dimitriadou, D. and Stalikas, A. (2017) Translation and Adaptation of Psychometric Tools. In: Galanakis, M., Pezirkianidis, C. and Stalikas, A., Eds., Basic Psychometric Issues, Topos Publications, Athens, 489-514.

[54] Cohen, P., Cohen, J., West, S.G. and Aiken, L.S. (2002) Applied Multiple Regression/Correlation Analysis for the Behavioral Sciences. Lawrence Earlbaum Associates, Hillsdale.

[55] Piedmont, R.L. (2014) Inter-Item Correlations. In: Michalos, A.C., Ed., Encyclopedia of Quality of Life and Well-Being Research, Springer, Dordrecht, 3303-3304. https://doi.org/10.1007/978-94-007-0753-5_1493 
[56] Williams, B., Onsman, A. and Brown, T. (2010) Exploratory Factor Analysis: A Five-Step Guide for Novices. Australasian Journal of Paramedicine, 8, 1-10.

[57] Hair, J., Black, W., Babin, B. and Anderson, R. (2010) Multivariate Data Analysis. 7th Edition, Prentice-Hall, Inc., Upper Saddle River.

[58] Hu, L.T. and Bentler, P.M. (1999) Cut-Off Criteria for Fit Indexes in Covariance Structure Analysis: Conventional Criteria versus New Alternatives. Structural Equation Modeling, 6, 1-55. https://doi.org/10.1080/10705519909540118

[59] Browne, M.W. and Cudeck, R. (1993) Alternative Ways of Assessing Model Fit. In: Bollen, K.A. and Long, J.S., Eds., Testing Structural Equation Models, Sage, Newbury Park, 136-162.

[60] Bentler, P.M. (1990) Comparative Fit Indexes in Structural Models. Psychological Bulletin, 107, 238-246. https://doi.org/10.1037/0033-2909.107.2.238

[61] Tucker, L.R. and Lewis, C. (1973) A Reliability Coefficient for Maximum Likelihood Factor Analysis. Psychometrika, 38, 1-10. https://doi.org/10.1007/BF02291170

[62] DeVellis, R.F. (2012) Scale Development: Theory and Applications. Sage, Los Angeles.

[63] Kyriazos, T. (2017) Reliability of Psychometric Instruments. In: Galanakis, M., Pezirkianidis, C. and Stalikas, A., Eds., Basic Psychometric Issues, Topos, Athens, 85-121.

[64] George, D. and Mallery, M. (2010) SPSS for Windows Step by Step: A Simple Guide and Reference, 17.0 Update, 10th Edition, Pearson, Boston.

[65] Davidshofer, K.R. and Murphy, C.O. (2005) Psychological Testing: Principles and Applications. 6th Edition, Pearson, Upper Saddle River.

[66] Cohen, J., Cohen, P., West, S.G. and Aiken, L.S. (2003) Applied Multiple Correlation/Regression Analysis for the Behavioral Sciences. Taylor and Francis, Abingdon-on-Thames.

[67] Wei, M., Heppner, P.P. and Mallinckrodt, B. (2003) Perceived Coping as a Mediator between Attachment and Psychological Distress: A Structural Equation Modeling Approach. Journal of Counseling Psychology, 50, 438-447. https://doi.org/10.1037/0022-0167.50.4.438

[68] Wei, M., Mallinckrodt, B., Russell, D.W. and Abraham, W.T. (2004) Maladaptive Perfectionism as a Mediator and Moderator between Adult Attachment and Depressive Mood. Journal of Counseling Psychology, 51, 201-212. https://doi.org/10.1037/0022-0167.51.2.201

[69] Mallinckrodt, B. and Wei, M. (2005) Attachment, Social Competence, Social Support, and Psychological Distress. Journal of Counseling Psychology, 52, 358-367. https://doi.org/10.1037/0022-0167.52.3.358

[70] Chan, Y.-C., Chan, F., Ditchman, N., Phillips, B. and Chou, C.C. (2013) Evaluating Snyder's Hope Theory as a Motivational Model of Participation and Life Satisfaction for Individuals with Spinal Cord Injury: A Path Analysis. Rehabilitation Research Policy and Education, 27, 171-185. https://doi.org/10.1891/2168-6653.27.3.171

[71] Davidson, O.B., Feldman, D.B. and Margalit, M. (2012) A Focused Intervention for 1st-Year College Students: Promoting Hope, Sense of Coherence, and Self-Efficacy. The Journal of Psychology, 146, 333-352. https://doi.org/10.1080/00223980.2011.634862

[72] Schiff, M. and Levit, S. (2009) Correlates of Therapeutic Alliance and Treatment Outcomes among Israeli Female Methadone Patients. Research on Social Work 
Practice, 20, 380-390. https://doi.org/10.1177/1049731509347854

[73] Giovazolias, T., Leontopoulou, S. and Triliva, S. (2010) Assessment of Greek University Students' Counselling Needs and Attitudes: An Exploratory Study. International Journal for the Advancement of Counselling, 32, 101-116.

https://doi.org/10.1007/s10447-010-9092-2

[74] Koutra, A., Katsiadrami, A. and Diakogiannis, G. (2008) The Effect of Group Psychological Counselling in Greek University Students' Anxiety, Depression, and Self-Esteem. European Journal of Counselling and Psychotherapy, 12, 101-111. https://doi.org/10.1080/13642537.2010.482733

[75] Brouzos, A., Vassilopoulos, S. and Korfiati, A. (2015) Secondary School Students' Perceptions of Their Counselling Needs in an Era of Global Financial Crisis: An Exploratory Study in Greece. International Journal for the Advancement of Counselling, 37, 168-178. https://doi.org/10.1007/s10447-015-9235-6

[76] Yotsidi, V., Bohtsou, V., Kroupi, K., Pouloudi, M. and Fragkouli, A. (2018) What Makes the Difference? Community Mental Health Providers' and Users' Perceptions on Dealing with the Crisis in Greece. Journal of Psychosocial Rehabilitation and Mental Health, 1-13. https://doi.org/10.1007/s40737-018-0106-4 